\author{
${ }^{\circ}$ И. Б. Вовк, Н. Е. Горбань, Т. А. Лысяная, Н. И. Нетреба, И. Г. Пономарева \\ ГУ «Институт педиатрии, акушерства и аинекологии \\ имени акаделика Е. М. Лукъяновой НАМН Украины»

\section{РОЛЬ ВОСПАЛИТЕЛЬНОГО ФАКТОРА В ГЕНЕЗЕ ГИПЕРПЛАСТИЧЕСКИХ ИЗМЕНЕНИЙ ЭНДОМЕТРИЯ У ЖЕНЩИН РЕПРОДУКТИВНОГО ВОЗРАСТА}

Цель исследования - выявить возможную роль микробного и вирусного фрактора в развитии неатипической гиперплазии эндометрия у женщин репродуктивного возраста и оценить степень экспрессии рецепторов стероидных гормонов (эстрогена и прогестерона) в патологически измененной ткани.

Материалы и методы. Нами были исследованы 60 образцов эндометрия у женщин с неатипической гиперплазией эндометрия. Группа контроля была представлена 10 здоровыми женщинами репродуктивного возраста без гинекологической патологии. Проведены иммуногистохимические исследования материала: определение экспрессивности ядерного рецептора - эстрогена с помощью непрямого стрептавидин-пероксидазного метода выявления экспрессии антител к рецепторам эстрогенов (Clone SP1) (производство Thermo scientific, моноклональные кроличьи антитела, рабочее разведение 1:100-1:400, система детекции UltraVision LP), прогестерона (Clone YR85) (производство Thermo scientific, моноклональные кроличьи антитела, рабочее разведение 1:25-1:50, система детекции UltraVision LP) с морфометрическим их анализом и выявление плазмоцитарных клеток CD-138 (Ab-2) (Syndecan-1) (производство Thermo scientific, мышиные антитела, рабочее разведение 1:10-1:20, система детекции UltraVision LP). Интенсивность иммуногистохимической реакции оценивали полуколичественным методом по 3-бальной шкале: «-/+» - отсутствие реакции; «++» - умеренная реакция; «+++»- выраженная реакция. Для каждого случая подсчитывался процент окрашенных с разной степенью интенсивности ядер. Распространенность реакции в цитоплазме оценивали полуколичественным методом следующим образом: 0 - нет окраски; 1 - менее 25 \% положительно окрашенных клеток; 2 - более 25 \% и менее 75 \% положительно окрашенных клеток; 3 - однородная окраска более $75 \%$ клеток.

Результаты исследования и их обсуждение. Перед проведением иммуногистохимического исследования гиперплазированной эндометриальной ткани нами проводился бактериологический и вирусологический анализ материала, полученного из полости матки с целью анализа микробного обсеменения у пациенток с неатипической гиперплазией эндометрия. Так, результаты данных исследований свидетельствуют о регистрации у всех пациенток с неатипической гиперплазией эндометрия различных видов микрофлоры, однако верифицированные титры в большинстве случаев не превышали $10^{2}-10^{3}$ степени. Согласно полученным результатам, в посевах из полости матки чаще всего на питательных средах высевались анаэробные микроорганизмы - Bacteroides, обнаруженные у 30,0 \% больных. Пациентки с неатипической гиперплазией эндометрия на современном этапе должны подвергаться не только бактериологическому и вирусологическому обследованию, но и иммуногистохимическому определению маркера CD-138, являющегося «золотым стандартом» подтверждения хронического эндометрита. Таким образом, хронический эндометрит является одним из важных патогенетических звеньев развития гиперплазии эндометрия, требующим не только своевременной и точной диагностики, но и новой тактики в подходах к лечению данной патологии, а именно на первом этапе назначения антибактериальной и противовирусной терапии в соответствии с результатами бактериально-вирусного обследования. Следовательно, мы можем говорить не только о гормонально-метаболическом пути развития гиперпластических процессов эндометрия, но и роли воспалительного фрактора в возникновении данной патологии.

Выводы. Приведены данные о роли микробного и вирусного фракторов в развитии неатипической гиперплазии эндометрия у женщин репродуктивного возраста. Установлена структура микробного обсеменения полости матки у таких женщин. Антигены вируса цитомегалии в гиперплазированном эндометрии выявлены в 38,3 \% случаев. Обнаружена гиперэкспрессия рецепторов стероидных гормонов в измененной эндометриальной ткани у женщин с неатипической гиперплазией эндометрия на сроне воспалительного процесса (CD-138 положительный), отличающаяся гетерогенностью и мозаицизмом экспрессии окрашивания, что, возможно, связано со степенью поражения клеточных элементов персистирующим влиянием бактериально-вирусного фрактора.

Ключевые слова: гиперплазия; эндометрий; рецептор; эндометрит; эстроген; прогестерон.

РОЛЬ ЗАПАЛЬНОГО ФАКТОРА В ГЕНЕЗІ ГІПЕРПЛАСТИЧНИХ ЗМІН ЕНДОМЕТРІЯ В ЖІНОК РЕПРОДУКТИВНОГО ВІКУ

Мета дослідження - виявити можливу роль мікробного і вірусного чинника у розвитку неатипової гіперплазії ендометрія в жінок репродуктивного віку й оцінити ступінь експресії рецепторів стероїдних гормонів (естрогену та прогестерону) в патологічно зміненій тканині.

Матеріали та методи. Ми дослідили 60 зразків ендометрія в жінок із неатиповою гіперплазією ендометрія. Група контролю була представлена 10 здоровими жінками репродуктивного віку без гінекологічної патології. Проведено імуногістохімічні дослідження матеріалу: визначення експресивності ядерного рецептора - естрогену за допомогою непрямого стрептавідинпероксидазного методу виявлення експресії антитіл до рецепторів естрогенів (Clone SP1) (виробництво Thermo scientific, моноклональні кролячі антитіла, робоче розведення 1:100 - 1:400, система детекції UltraVision LP), прогестерону (Clone YR85) (виробництво Thermo scientific, моноклональні кролячі антитіла, робоче розведення 1:25-1:50, система детекції UltraVision LP) з морфометричним їх аналізом і виявлення плазмоцитарних клітин CD-138 (Ab-2) (Syndecan-1) (виробництво Thermo scientific, мишачі антитіла, робоче розведення 1:10-1:20, система детекції UltraVision LP). Інтенсивність імуногістохімічної 
реакції оцінювали напівкількісним методом за 3-бальною шкалою: «-/+» - відсутність реакції; «++»- помірна реакція; «+++» - виражена реакція. Для кожного випадку підраховується відсоток забарвлених із різним ступенем інтенсивності ядер. Поширеність реакції в цитоплазмі оцінювали напівкількісним методом таким чином: 0 - немає забарвлення; 1 - менше 25 \% позитивно забарвлених клітин; 2 - більше 25 \% і менше 75 \% позитивно забарвлених клітин; 3 - однорідне забарвлення більше 75 \% клітин.

Результати дослідження та їх обговорення. Перед проведенням імуногістохімічного дослідження гіперплазованої ендометріальної тканини ми проводили бактеріологічний і вірусологічний аналіз матеріалу, отриманого з порожнини матки з метою аналізу мікробного обсіменіння у пацієнток із неатиповою гіперплазією ендометрія. Так, результати даних досліджень свідчать про реєстрацію у всіх пацієнток із неатиповою гіперплазією ендометрія різних видів мікрослори, однак верифіковані титри в більшості випадків не перевищували $10^{2}-10^{3}$ ступеня. Згідно 3 отриманими результатами, у посівах з порожнини матки найчастіше на поживних середовищах висівали анаеробні мікроорганізми - Васteroides, виявлені у 30,0 \% хворих. Пацієнткам із неатиповою гіперплазією ендометрія на сучасному етапі призначали не тільки бактеріологічне і вірусологічне обстеження, а й здійснення імуногістохімічного визначення маркера CD-138, що є «золотим стандартом» підтвердження хронічного ендометриту. Таким чином, хронічний ендометрит є однією 3 важливих патогенетичних ланок розвитку гіперплазії ендометрія, що вимагає не тільки своєчасної та точної діагностики, але і нової тактики в підходах до лікування даної патології, а саме на першому етапі призначення антибактеріальної і противірусної терапії відповідно до результатів бактеріально-вірусного обстеження. Отже, ми можемо говорити не тільки про гормонально-метаболічний шлях розвитку гіперпластичних процесів ендометрія, а й роль запального фактора у виникненні даної патології.

Висновки. Наведені дані про роль мікробного і вірусного фракторів у розвитку неатипової гіперплазії ендометрія в жінок репродуктивного віку. Встановлено структуру мікробного обсіменіння порожнини матки в таких жінок. Антигени вірусу цитомегалії в гіперплазованому ендометрії виявлені в 38,3 \% випадків. Визначена гіперекспресія рецепторів стероїдних гормонів у зміненій ендометріальній тканині в жінок із неатиповою гіперплазією ендометрія на тлі запального процесу (CD-138 позитивний), що відрізняється гетерогенністю і мозаїцизмом експресії зафарбовування, що, можливо, пов'язано зі ступенем ураження клітинних елементів персистуючим впливом бактеріально-вірусного чинника.

Ключові слова: гіперплазія; ендометрій; рецептор; ендометрит; естроген; прогестерон.

THE ROLE OF THE INFLAMMATORY FACTOR IN THE GENESIS OF HYPERPLASTIC CHANGES OF ENDOMETRIUM IN WOMEN OF REPRODUCTIVE AGE

The aim of the study - to identify the possible role of microbial and viral factors in the development of non-typical endometrial hyperplasia in women of reproductive age and assess the degree of expression of steroid hormone receptors (estrogen and progesterone) in pathologically altered tissue.

Materials and Methods. We investigated 60 endometrial specimens in women with non-atypical endometrial hyperplasia. The control group was represented by 10 healthy women of reproductive age without gynecological pathology. Immunohistochemical studies of the material were performed: determination of the expressiveness of the nuclear receptor - estrogen using an indirect streptavidin-peroxidase method for detecting expression of antibodies to estrogen receptors (Clone SP1) (manufactured by Thermo scientific, monoclonal rabbit antibodies, working dilution 1: 100 - 1: 400, UltraVision detection system LP), progesterone (Clone YR85) (production of Thermo scientific, monoclonal rabbit antibodies, working dilution 1: 25-1: 50, UltraVision LP detection system), with their morphometric analysis and identification of plasmacytic cells CD-138 (Ab-2) (Syndecan-1) (manufactured Thermo scientific, murine, working dilution 1: 10-1: 20, UltraVision LP Detection System). The intensity of the immunohistochemical reaction was evaluated by a semi-quantitative method on a 3-point scale: "- / +" - no reaction, "++" - moderate reaction; "+++" is a pronounced reaction. For each case, the percentage of nuclei stained with varying degrees of intensity was calculated. The prevalence of the reaction in the cytoplasm was assessed by a semi-quantitative method as follows: 0 - no color; 1 - less than $25 \%$ positively stained cells; 2 - more than $25 \%$ and less than $75 \%$ of positively stained cells; 3 - homogeneous staining of more than $75 \%$ of cells.

Results and Discussion. Before conducting an immunohistochemical study of a hyperplastic endometrial tissue, we carried out a bacteriological and virological analysis of material obtained from the uterus to analyze microbial dissemination in patients with non-atypical endometrial hyperplasia. Thus, the results of these studies indicate the registration of different types of microflora in all patients with non-atypical endometrial hyperplasia, however, the verified titers in most cases did not exceed 102-103 degrees. According to the obtained results, in crops from the uterus, most often on nutrient media, anaerobic microorganisms were sown - Bacteroides, found in $30.0 \%$ of patients. Patients with non-atypical endometrial hyperplasia at the present stage should be subjected not only to bacteriological and virological examination, but also to the immunohistochemical determination of the marker CD-138, which is the "gold standard" of confirmation of chronic endometritis. Thus, chronic endometritis is one of the important pathogenetic links in the development of endometrial hyperplasia, which requires not only timely and accurate diagnosis, but also new tactics in approaches to the treatment of this pathology, namely, at the first stage of prescribing antibacterial and antiviral therapy in accordance with the results of bacterial - virus examination. Consequently, we can speak not only about the hormonal and metabolic pathway of the development of endometrial hyperplastic processes, but also the role of the inflammatory factor in the occurrence of this pathology.

Conclusions. The data on the role of microbial and viral factors in the development of nonatypical endometrial hyperplasia in women of reproductive age is presented. The structure of microbial seeding of the uterine cavity in such women was established. Cytomegalovirus antigens in the hyperplastic endometrium were detected in $38.3 \%$ of cases. Overexpression of steroid hormone receptors was found in modified endometrial tissue in women with nonatypical endometrial hyperplasia during an inflammatory process (CD-138 positive), which is distinguished by heterogeneity and mosaicism of staining expression, which may be due to the degree of damage to cellular elements by the persistent effect of bacterial virus.

Key words: hyperplasia; endometrium; receptor; endometritis; estrogen; progesterone. 
ВСТУПЛЕНИЕ. На сегодняшний день, согласно последним международным протоколам, гиперплазия эндометрия характеризуется как мультифракториальная проблема: с позиций онконастороженности (как предшественник аденокарциномы эндометрия), с четким морфологическим определением ее как неравномерной неинвазивной пролисерации эндометриальных желез с увеличением соотношения желез к строме в сравнении с эндометрием пролиферативного типа и с установленной этиологической причиной в виде непрерывной стимуляции эндометрия эстрогенами без оппозиционного влияния адекватных уровней прогестерона [18-21], что реализуется сложным путем активации связей на рецепторном уровне в клетках эндометрия [23].

Анализ научных обзоров показывает, что около 52-74 \% больных с гиперпролиферативными заболеваниями эндометрия, которые получали гормональную терапию, сталкиваются с персистенцией заболевания, с неудовлетворительными результатами хирургического лечения, отсутствием полноценной ремиссии после органосохраняющих операций [8]

Несмотря на наличие большого количества исследований по данной проблеме, вопросы адекватной диагностики и подходов к тактике лечения таких заболеваний до сих пор остаются предметом научного поиска, что заставило нас анализировать различные патогенетические звенья в формировании гиперпластических изменений эндометриальной ткани для выявления их возможного патологического влияния.

Так, на сегодняшний день актуальность приобретает теория о хроническом воспалении матки, при котором происходит искажение реализации действия эстрогенов на эндометрий и угнетение фуункциональной активности нейтрофилов, что приводит к возникновению иммунного дисбаланса [2, 3].

Следует отметить, что бактериально-вирусная иноекция имеет иммунодепрессивное влияние на организм, что является основой для фрормирования патологического процесса. Хронический воспалительный процесс инициирует дистрофические изменения эпителия, нарушения межклеточных контактов и инфильтрацию стромы лейкоцитами и лимфоцитами. Снижается герметизация покровного эпителия, уменьшается количество гликогена и нарушается диффреренцировка клеток в процессе метаплазии. Одновременно возникает вторичный местный иммунодефицит клеточных и гуморальных иммунных реакций [5-7].

Имеются единичные работы об исследовании микрофрлоры у женщин с простой гиперплазией эндометрия, в котором указывается, что в 62,3 \% пациенток репродуктивного возраста в полости матки обнаруживаются инфекционные агенты неспецифической этиологии при отсутствии достоверных клиниколабораторных, ультразвуковых, гистероскопических и патоморфологических маркеров воспалительного процесса в эндометрии [4].

Отдельные авторы отмечают, что отсутствие роста микрофрлоры из полости матки не исключает наличие иноекционных агентов в ткани эндометрия [10-12]. В исследовании, проведенном В. Е. Радзинским и соавт. (2017), удельный вес аутоиммунного эндометрита составил $28,4 \%(n=98)$ от общего числа пациенток с нарушениями в репродуктивной системе $(n=345)$ [17]. При этом роль вирусного инфицирования изучено недостаточно, не установлен видовой спектр, а также вопрос о влиянии на возможность возникновения гиперпластических процессов эндометрия до сих пор не получил однозначного ответа.

Также, учитывая стратегию онконастороженности в современном медицинском мире, следует отметить появление единичных работ о возможной роли микробиома в этоилогии и прогрессировании рака эндометрия [1], предшественником которого, по данным современных протоколов, в ряде случаев является гиперплазия эндометрия [22]. Следует учитывать, что заболеваемость гиперплазиями эндометрия оценивается по меньшей мере в три раза выше, чем раком эндометрия, и при отсутствии лечения может прогрессировать до рака эндометрия [13, 14].

Низкая эфффективность лечебно-профилактических мероприятий на современном этапе объясняется отсутствием этиологической направленности вследствие недостаточного представления об основных механизмах гиперпролиферативных процессов в матке [9].

Целесообразность детализации патогенетических аспектов гиперпролиферативной патологии эндометрия обусловлена улучшением диагностики и включением в терапию мероприятий, связанных с изменениями фрункций различных компонентов иммунной системы и участием инфекционного фактора. Только комплексный подход к решению проблемы гиперпролиферативных заболеваний эндометрия позволит разработать эффрективный алгоритм ведения этой категории пациенток.

ЦЕЛЬ ИССЛЕДОВАНИЯ - ВЫЯВИТЬ ВОЗмОЖНУю роЛЬ микробного и вирусного фрактора в развитии неатипической гиперплазии эндометрия у женщин репродуктивного возраста и оценить степень экспрессии рецепторов стероидных гормонов (эстрогена и прогестерона) в патологически измененной ткани.

МАТЕРИАЛЫ И МЕТОДЫ. Нами были исследованы 60 образцов эндометрия у женщин с неатипической гиперплазией эндометрия. Группа контроля была представлена 10 здоровыми женщинами репродуктивного возраста без гинекологической патологии. Проведены иммуногистохимические исследования материала: определение экспрессивности ядерного рецептора эстрогена с помощью непрямого стрептавидин-пероксидазного метода выявления экспрессии антител к рецепторам эстрогенов (Clone SP1) (производство Thermo scientific, моноклональные кроличьи антитела, рабочее разведение 1:100-1:400, система детекции UltraVision LP), прогестерона (Clone YR85) (производство Thermo scientific, моноклональные кроличьи антитела, рабочее разведение 1:25-1:50, система детекции UltraVision LP) с морфометрическим их анализом и выявление плазмоцитарных клеток CD-138 (Ab-2) (Syndecan-1) (производство Thermo scientific, мышиные антитела, рабочее разведение 1:10-1:20, система детекции UltraVision LP).

Интенсивность иммуногистохимической реакции оценивали полуколичественным методом по 3-бальной шкале: «-/+» - отсутствие реакции; «++» - умеренная реакция; «+++» - выраженная реакция. Для каждого случая подсчитывался процент окрашенных с разной степенью интенсивности ядер. 
Распространенность реакции в цитоплазме оценивали полуколичественным методом следующим образом: 0 - нет окраски; 1 - менее 25 \% положительно окрашенных клеток; 2 - более 25 \% и менее 75 \% положительно окрашенных клеток; 3 - однородная окраска более $75 \%$ клеток.

Оценка результатов - использование светового микроскопа Olympus BX 51 (Япония). Для обработки данных использовали стандартные статистические процедуры с помощью Microsoft Excel.

Все исследования проводились в ГУ «Институт педиатрии, акушерства и гинекологии имени академика Е. М. Лукьяновой НАМН Украины» (лаборатория патоморфологии, руководитель - член-корреспондент НАМН Украины, профрессор Т. Д. Задорожная; лаборатория микробиологии, руководитель - кандидат биологических наук Т. А. Лысяная; лаборатория вирусологии, руководитель - кандидат биологических наук Н. И. Нетреба).

Гистологическое исследование проводилось в соответствии с протоколом показателей нормального эндометрия с учетом фразы и дня менструального цикла, согласно классических критериев R. W. Noyes и соавт. $[3,4]$ и Протокола исследования эндометрия, разработанного в лаборатории патоморфологии ГУ «Институт педиатрии, акушерства и гинекологии имени академика Е. М. Лукьяновой НАМН Украины» (утверждено РПК «Патологическая анатомии» МЗ Украины и АМН Украины от 22.01.2010 г., ученым советом Института от 15.02.2018 г.).

Все исследованные образцы были верифицированы согласно классисрикации Всемирной организации здравоохранения (2014) как гиперплазия эндометрия без атипии (отсутствуют признаки цитологической атипии).

Бактериологический анализ материала из полости матки включал исследования аэробной (стафилококк, стрептококк, кишечная палочка, энтеробактерии, грибы рода Candida и т. д.) и анаэробной фрлоры (лактобациллы, бактероиды и т. п.) с использованием набора селективных дифференциально-диагностических питательных сред. Во всех высеянных культурах изучали морфологические, бактериальные, культуральные и биологические свойства.

Для выявления степени вирусной нагрузки использован непрямой метод Кунса в модификации с использованием меченых моноклональных антител к цитомегалии и генитальному герпесу, оценка результатов производилась с помощью люминесцентного микроскопа (ЛЮМАМ-І 1). Анализ количественной нагрузки обсеменения эндометриальной ткани производился по степени экспрессии от «0» до «4» («0» - отсутствие признаков антигена; «+»-степень экспрессии антигенов сомнительная; «++»- степень экспрессии антигенов слабопозитивная; «+++»-степень экспрессии антигенов позитивная; «++++» - степень экспрессии антигенов резкопозитивная).

РЕЗУЛЬТАТЫ ИССЛЕДОВАНИЯ И ИХ ОБСУЖДЕ-

HИЕ. Перед проведением иммуногистохимического исследования гиперплазированной эндометриальной ткани нами проводился бактериологический и вирусологический анализ материала, полученного из полости матки с целью анализа микробного обсеменения у пациенток с неатипической гиперплазией эндометрия.

Так, результаты данных исследований свидетельствуют о регистрации у всех пациенток с неатипической ги- перплазией эндометрия различных видов микрофрлоры, однако верифицированные титры в большинстве случаев не превышали $10^{2}-10^{3}$ степени.

Согласно полученным результатам, в посевах из полости матки чаще всего на питательных средах высевались анаэробные микроорганизмы-Bacteroides, обнаруженные у 30,0 \% больных.

В спектр аэробной грамположительной микрофрлоры, выделенной из полости матки, чаще всего входили S. faecalis $(20,0 \%)$, Str. agalactiae (13,3\%), St. epidermidis (гем) (16,7 \%) и St. epidermidis (11,7\%).

Среди энтеробактерий зарегистрировано наибольшую частоту контаминации полости матки E. coli - y 21,7 \% пациенток. С меньшей частотой высевались Enterobacter spp. (11,7 \%) и Klebsiella spp. (6,7\%).

Грибы рода Candida выделялись из полости матки только в 5,0 \% обследованных.

Полный спектр выявленных микроорганизмов представлен на диаграмме (рис. 1).

Как свидетельствуют данные, представленные на рисунке 1, в посевах из полости матки у женщин с гиперпролиферативной патологией эндометрия анаэробы составили около трети от всех выделенных микроорганизмов. Примечательно, что среди них преобладали грамотрицательные бактерии рода Bacteroides. Среди аэробных микроорганизмов преобладали представители семейства Enterobacteriaceae, в частности E. coli и граммположительные кокки (стафилококки и стрептококки).

Наличие бактерий рода Enterococcus и других условно-патогенных микроорганизмов в несвойственном для них биотопе - полости матки - может свидетельствовать о процессе транслокации их из кишечного биотопа на фоне снижения колонизационной резистентности слизистых оболочек у женщин с гиперпластическими заболеваниями эндометрия.

Широкий спектр выделенных представителей семейства Enterobacteriaceae у обследованных пациенток указывает на неблагополучие в исследуемом биотопе, а выявление золотистого стафилококка, который является патогеном, свидетельствует о наличии хронического очага воспаления (хронического течения заболевания) в организме женщины.

С целью верифрикации диагноза хронического эндометрита нами проведено иммуногистохимическое исследование гиперплазированного эндометрия на маркер CD-138, являющийся современным индикатором наличия хронического эндометрита.

Было установлено, что из 60 больных с неатипической гиперплазией эндометрия у 19 (31,7\%) определялось наличие структурно-морфологических признаков хронического эндометрита, что подтверждалось иммуногистохимически наличием маркера воспаления CD-138, в то время как при бактериологическом исследовании содержимого из полости матки микрофрлора выявлялась у всех обследованных больных.

Для выявления возможной роли вирусной нагрузки в гиперплазированном эндометрии при наличии хронического воспалительного процесса нами параллельно был проведен анализ вирусологического спектра в мазках-отпечатках обследованных пациенток. Так, было установлено, что у 38,3 \% обследованных в 


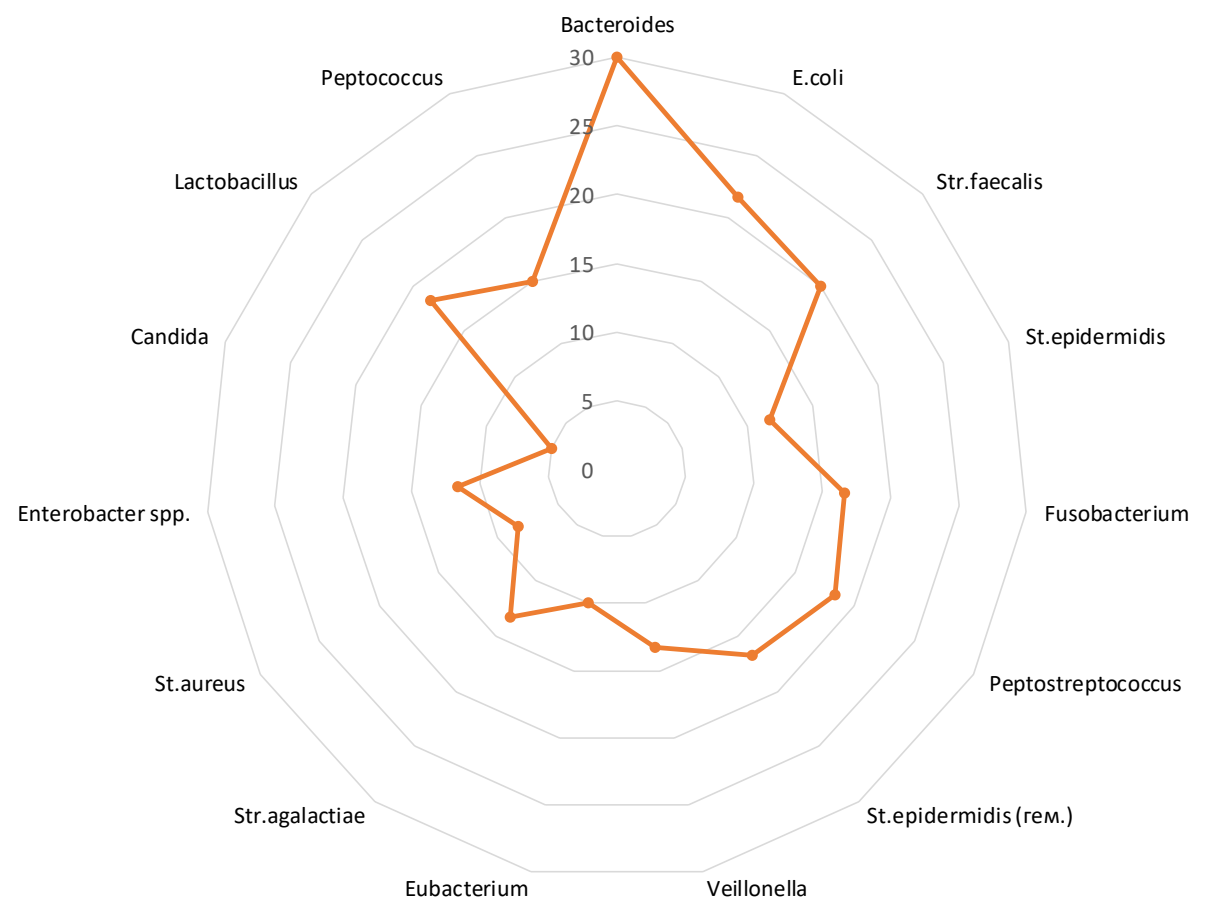

Рис. 1. Структура микробного обсеменения полости матки у пациенток репродуктивного возраста с неатипической гиперплазией эндометрия, \%.

органе-мишени - эндометрии - обнаруживались положительная экспрессия антигенов вируса цитомегалии в диагностически значимых концентрациях (рис. 2), в то время как антигены вируса генитального герпеса экспрессировались в гиперплазированном эндометрии достоверно реже - всего у 8,3 \% пациенток.

Полученные данные позволили нам предположить мультифракториальный генез развития неатипической гиперплазии эндометрия, где бактериально-вирусному срактору отводится не последняя роль.

Это дает основания считать, что гиперплазия эндометрия у части больных может фрормироваться в условиях локального персистирования вирусных частиц с соответствующим их негативным влиянием на жизненный цикл клеток и в условиях хронического воспалительного процесса в органе потенцирует возникновение нарушений в репродуктивной системе женщины.

На основании вышеизложенного материала нам представляется логичным, что первоочередным вопросом в выборе подходов к диагностике причин возникновения гиперпластических процессов эндометрия у женщин репродуктивного возраста должно быть исследование микробного обсеменения с последующим включением этапа антибактериальной терапии до проведения гормональной коррекции в схему персонисицированного подхода к ведению таких пациенток.

Но, принимая во внимание, что все же фрнкциональная активность эндометрия постоянно находится под контролируемым влиянием циклической секреции стероидных гормонов, благодаря высокоафинным рецепторам к стероидам [9], нами были проанализированы степени экспрессии эстрогеновых и прогестероновых рецепторов в эпителиальном и стромальных компонентах гиперплазированного эндометрия больных репро-

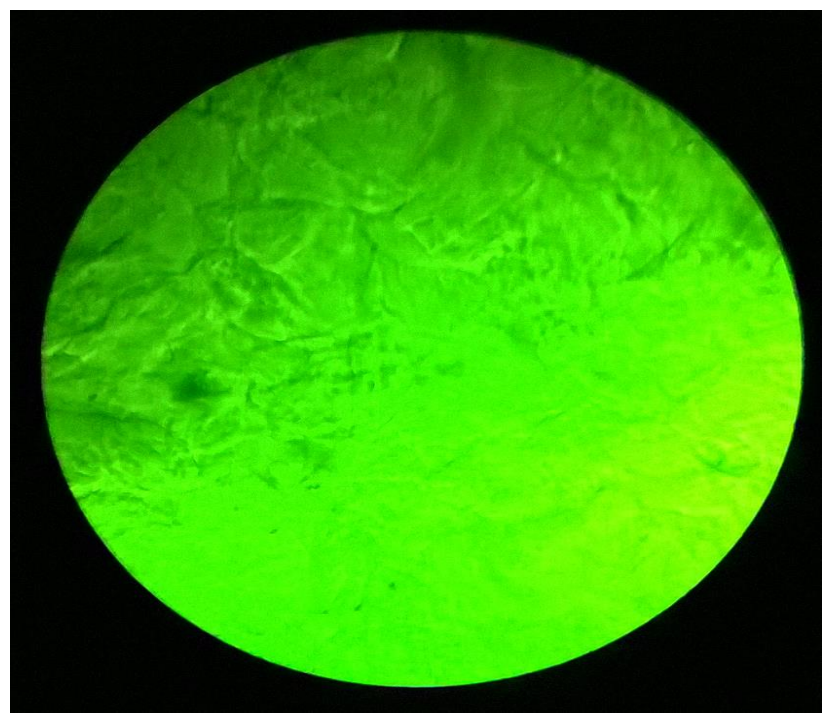

Рис. 2. Специфическая люминесценция антигенов вируса цитомегалии. Непрямой метод Кунса в модисрикации с применением меченых фрлуоресцирующим красителем моноклональных антител к ЦМВ. Положительная реакция («+++»). Микрофотограсрия. Об.×90. Ок.×5.

дуктивного возраста в динамике менструального цикла в зависимости от наличия или отсутствия признаков воспалительного процесса (экспрессия CD-138 в гиперплазированном эндометрии).

Это было важным и с позиции выявления глубины поражения морфологических структур рецепторного аппарата при наличии бактериально-вирусных фракторов. Полученные результаты сравнивались со степенью 
экспрессии эстрогеновых и прогестероновых рецепторов у здоровых женщин.

Так, при исследовании эндометрия пролиферативной фразы менструального цикла у здоровых женщин отмечена однородная и интенсивная экспрессия как эстрогеновых, так и прогестероновых рецепторов, что выражалось экспрессией эстрогеновых рецепторов на уровне $100 \%$ в клетках эпителия железистого компонента и 90 \% в стромальном компоненте. Экспрессия прогестероновых рецепторов при этом в железистом компоненте отмечалась в $90 \%$, в стромальном - в $70 \%$ соответственно.

При подсчете интенсивности выраженности экспрессии изучаемых рецепторов в пролисеративной фразе менструального цикла у пациенток с неатипической гиперплазией эндометрия на фоне воспалительного процесса (положительный CD-138) нами были отмечены выраженная гетерогенность и мозаицизм экспрессии эстрогеновых рецепторов как в пролиферативную, так и в секреторную фразы цикла в клетках эпителия железистого компонента (на уровне 90-95 \% соответственно) при более однородно сохраненных показателях гиперэкспрессии рецепторов в эпителии стромы - на 85-95 \%.

Прогестероновые рецепторы в пролисреративной фазе менструального цикла у пациенток с неатипической гиперплазией эндометрия на фроне воспалительного процесса также имели достаточно сниженные стромальные показатели (до 50 \%) на фоне не такого значительного снижения интенсивности экспрессии рецепторов прогестерона в клетках эпителия желез (до 75 \%).

При анализе показателей средней секреторной фразы менструального цикла у здоровых женщин выявлялось резкое снижение экспрессии эстрогеновых рецепторов в клетках эпителия железистого компонента до 20-25 \%, в клетках эпителия стромы этот показатель достигал 30 \%. Однонаправленная реакция рецепторной экспрессии наблюдалась и в динамичном изменении высоких показателей прогестерона во второй фразе у здоровых женщин - выявление на уровне 80 \% в железистом и 90 \% в стромальном компонентах неизмененного эндометрия, что сочетается с выводами других авторов [17].

Значительные изменения рецептивности эстрогеновых рецепторов наблюдались во второй половине менструального цикла у пациенток с гиперплазией эндометрия на фроне хронического эндометрита, что выявлялось повышенной экспрессией - до $95 \%$ в клетках эпителия железистых структур и до 90 \% в клетках эпителия стромы, являясь признаком несостоявшейся секреторной трансформации эндометриальной ткани. Как и в пролиферативной фразе менструального цикла, экспрессия эстрогеновых рецепторов отличалась выраженной гетерогенностью интенсивности окрашивания, что проявлялось даже единичными участками с отсутствием рецептивности, что может развиваться на фоне длительно персистирующего воспалительного процесса, приводящего к явлениям фриброзирования стромы, которые способствуют асинхронности работы рецепторного аппарата и приводят к неполноценной секреторной трансформации эндометрия, вызывая его патологические изменения [15].

Что касается выраженности экспрессии прогестероновых рецепторов в секреторной фазе цикла, при неатипической гиперплазии эндометрия на фоне воспалительного процесса, эти показатели были снижены по сравнению с таковыми у здоровых женщин и составили в клетках эпителия желез около 50 \%, а в эпителии стромы - до 60 \%, при этом характерной особенностью их была гетерогенность интенсивности прокрашивания клеток.

Полученные результаты позволяют рассматривать наличие иноекционных патогенов в эндометрии как один из возможных триггеров развития гиперпластических процессов, приводящих к морфоорункциональным его нарушениям с изменением экспрессии эстрогеновых и прогестероновых рецепторов.

Пациентки с неатипической гиперплазией эндометрия на современном этапе должны подвергаться не только бактериологическому и вирусологическому обследованию, но и иммуногистохимическому определению маркера CD-138, являющегося «золотым стандартом» подтверждения хронического эндометрита.

Таким образом, хронический эндометрит является одним из важных патогенетических звеньев развития гиперплазии эндометрия, требующим не только своевременной и точной диагностики, но и новой тактики в подходах к лечению данной патологии, а именно на первом этапе назначения антибактериальной и противовирусной терапии в соответствии с результатами бактериальновирусного обследования. Следовательно, мы можем говорить не только о гормонально-метаболическом пути развития гиперпластических процессов эндометрия, но и роли воспалительного фрактора в возникновении данной патологии.

ВыВоды. 1. У пациенток репродуктивного возраста с неатипической гиперплазией эндометрия персистенция бактериальных агентов в содержимом полости матки в незначительной концентрации отмечена у всех обследованных, вирусных - 38,3 \%, что отражает значительную этиологическую роль бактериально-вирусного инфицирования, участвующего в реализации воспалительного процесса и формировании гиперпролисеративной патологии.

2. Морфологические признаки хронического эндометрита у женщин репродуктивного возраста с неатипической гиперплазией эндометрия с помощью маркера CD-138 выявляются у трети пациенток - в 31,7 \%.

3. Гиперэкспрессия рецепторов стероидных гормонов при наличии неатипической гиперплазии эндометрия у женщин репродуктивного возраста сочетается с признаками явной гетерогенности их выраженности, что, возможно, связано со степенью поражения клеточных элементов персистирующим влиянием бактериальновирусного фрактора.

4. Выявление морфологических признаков воспалительного процесса в гиперплазированном эндометрии с анализом спектра его возможных возбудителей обосновывает необходимость проведения противовоспалительной и противовирусной терапии до назначения протокольного гормонального лечения.

ПЕРСПЕКТИВЫ ДАЛЬНЕЙШИХ ИССЛЕДОВАНИЙ. Учитывая доказанную роль воспалительного фрактора как одного из триггерных моментов в развитии неатипической гиперплазии эндометрия, перспективными представляются исследования в данном направлении при наличии иных типов пролифреративных процессов 
эндометрия, например при полипах тела матки. Что касается установленной измененной рецептивности стероидных гормонов в гиперплазированном эндометрии

\section{СПИСОК ЛИТЕРАТУРЬ}

1. Potential contribution of the uterine microbiome in the development of endometrial cancer / M. R. Walther-António, J. Chen, F. Multinu [et al.] // Genome Med. - 2016. - Vol. 8 (1). - P. 122.

2. The diagnosis of chronic endometritis in infertile asymptomatic women: a comparative study of histology, microbial cultures, hysteroscopy, and molecular microbiology / I. Moreno, E. Cicinelli, I. Garcia-Grau [et al.] // Am. J. Obstet. Gynecol. 2018. - Vol. 218 (6). - P. 602.

3. Морфоорункциональное состояние эндометрия у женщин с бактериально-вирусным эндометритом / Л. И. Мальцева, Р. И. Шарипова, Д. Э. Цыплаков, М. Е. Железова // Практическая медицина. - 2017. - Т. 7 (108). - С. 87-91.

4. Состояние микроценоза полости матки у пациенток с простыми гиперплазиями эндометрия / И. И. Куценко, Э. Р. Аракелян, И. О. Боровиков, Ю. С. Сафронова // Современные проблемы науки и образования. - 2014. № 2. - C. 283.

5. Микрофлора влагалища и цервикального канала у женщин с полипами шейки матки / О. В. Макаров, Т. Н. Савченко, В. А. Алёшкин [и др.] // Вестник Российского государственного медицинского университета. - 2011. № 4. - С. 43-47.

6. Подольський Вл. В. Стан мікробіоценозу урогенітальних органів у жінок з порушенням репродуктивного здоров'я та змінами вегетативного гомеостазу / Вл. В. Подольський, Т. О. Лісяна, І. Г. Пономарьова // Здоровье женщины. -2015 - № 2. - C. 142-150.

7. Пономаренко К. Ю. Рецептивность эндометрия у женщин с нарушениями в репродуктивной системе / К. Ю. Пономаренко // Журнал акушерства и женских болезней. - 2017. - Т. 66, № 4. - С. 90-97.

8. Лукач А. А. Гиперпластические процессы гениталий, ассоциированные с инсееционными патогенами (патогенез, клиника, диагностика) : автореф. дисс. на соискание ученой степени д-ра мед. наук / А. А. Лукач. - М., 2010. - 43 с.

9. Особливості аеробної та анаеробної мікрофрлори у жінок 3 гіперпроліферативними захворюваннями матки і ендометрія / І. Б. Вовк, А. Г. Корнацька, Т. О. Лисяна [та ін.] // Здоровье женщины. - 2016. - № 2. - С. 102-106.

10. Даньшина А. В. Микроэкологические особенности компонентов биопленки репродуктивного тракта женщин : автореф. дисс. на соискание ученой степени канд. биол. наук / А. В. Даньшина. - Ульяновск, 2012. - 22 с.

\section{REFERENCES}

1. Walther-António, M.R., Chen, J., Multinu, F., Hokenstad, A., Distad, T.J., Cheek, E.H., ... \& Mariani, A. (2016). Potential contribution of the uterine microbiome in the development of endometrial cancer. Genome Med., 25, 8 (1), 122.

2. Moreno, I., Cicinelli, E., Garcia-Grau, I., GonzalezMonfort, M., Bau, D., Vilella, F., ... \& Simon, C. (2018). The diagnosis of chronic endometritis in infertile asymptomatic (эстрогеновых и прогестероновых рецепторов), важными являются поиск возможных вспомагательных маркеров прогнозирования таких состояний, поиск патогенетически обоснованных подходов к ведению таких пациенток.

11. Franasiak J. M. Reproductive tract microbiome in assisted reproductive technologies / J. M. Franasiak, R. T. Jr. Scott // Fertil. Steril. - 2015. - Vol. 104 (6). - P. 1364-1371.

12. Доброхотова Ю. Э. Микробиота репродуктивного тракта и гиперпластические процессы эндометрия (обзор литературы) / Ю. Э. Доброхотова, К. К. Якубова // РМЖ. Медицинское обозрение. - 2018. - № 10. - С. 14-16.

13. Kurman R. J. The behavior of endometrial hyperplasia. A long-term study of "untreated" hyperplasia in 170 patients / R. J. Kurman, P. F. Kaminski, H. J. Norris // Cancer. - 1985. Vol. 56. - P. 403-412.

14. Incidence of endometrial hyperplasia / S. D. Reed, K. M. Newton, W. L. Clinton [et al.] // Am. J. Obstet. Gynecol. 2009. - Vol. 200 (6). - P. 678.e1-678.e6.

15. Lax S. F. Endometritis: Rare disease with clinical importance? / S. F. Lax / Der Pathologe. - 2016. - Vol. (6). P. 521-525. doi: 10.1007/s00292-016-0237-x

16. Патогенетические особенности макротипов хронического эндометрита / В. Е. Радзинский, Ю. А. Петров, Е. А. Калинина [и др.] // Казанский медицинский журнал. 2017. - № 1 (98). - С. 27-34.

17. Иммуногистохимические исследования экспрессии рецепторов стероидных гормонов в эндометрии женщин в ходе нормального менструального цикла / М. Х. Ашхаб, А. Л. Владимирцева, Н. Н. Шелястина, И. И. Бабиченко // Вестник РУДН. Серия «Медицина». - 2002. - № 1.

18. Табакман Ю. Ю. Рак эндометрия : руководство для врачей / Ю. Ю. Табакман. - М. : Практическая медицина, 2009. - 172 c.

19. ACOG Committee Opinion No. 631. "Endometrial intraepithelial neoplasia." Obstet Gynecol. - 2015. - Vol. 125. P. 1272-1278.

20. WHO Classification of Tumours of Female Reproductive Organs. 4th ed. / R. J. Kurman, M. L. Carcangiu, C. S. Herrington, R. H. Young editors. - Lyon : IARC, 2014.

21. Керівництво по клінічному веденню гіперплазії ендометрія Гонконгського коледжу акушерів і гінекологів (HKCOG) від вересня 2015 року № 16.

22. Керівництво Королівського коледжу акушерів і гінекологів (RCOG) та Британського товариства з гінекологічної ендоскопії (BSGE) від лютого 2016 року № 67.

23. Сергеев П. В. Рецепторы фризиологически активных веществ / П. В. Сергеев, Н. Л. Шиманович, В. И. Петров. Волгоград : Семь ветров, 1999.

women: a comparative study of histology, microbial cultures, hysteroscopy, and molecular microbiology. Am. J. Obstet. Gynecol., 218 (6), 602.

3. Maltseva, L.I., Sharipova, R.I., Tsyplakov, D.E., \& Zhelezova, M.Ye. (2017). Morfofunktsionalnoye sostoyaniye endometriya $u$ zhenshchin $\mathrm{s}$ bakterialno-virusnym endometritom [Morphofunctional state of the endometrium in women with 
bacterial viral endometritis]. Prakticheskaya meditsina - Practical Medicine, 7 (108), 87-91 [in Russian].

4. Kutsenko, I.I., Arakelyan, E.R., Borovikov, I.O., \& Safronova, Yu.S. (2014). Sostoyaniye mikrotsenoza polosti matki u patsiyentok s prostymi giperplaziyami endometriya [The state of uterine cavity microcenosis in patients with simple endometria hyperplasias]. Sovremennyye problemy nauki i obrazovaniya Modern Problems of Science and Education, 2, 283 [in Russian]

5. Makarov, O.V., Savchenko, T.N., Aloshkin, V.A., Afanasyev, S.S., Voropayeva, Ye.A., Melnikov, A.V., \& Batiyan, T.S (2011). Mikroflora vlagalishcha i tservikalnogo kanala u zhenshchin s polipami sheyki matki [Vaginal and cervical microflora in women with cervical polyps]. Vestnik Rossiyskogo gosudarstvennogo meditsinskogo universiteta - Bulletin of the Russian State Medical University, (4), 43-47 [in Russian].

6. Podolskyi, VI.V., Lisiana, T.O., \& Ponomarova, I.H. (2015) Stan mikrobiotsenozu urohenitalnykh orhaniv u zhinok z porushenniam reproduktyvnoho zdorovia ta zminamy vehetatyvnoho homeostazu [Condition of microbiocenosis of urogenital organs in women with reproductive health and changes in vegetative homeostasis]. Zdorovye zhenshchiny - Health of a Woman, 2 , 142-150 [in Ukrainian].

7. Ponomarenko, K.Yu. (2017). Retseptivnost endometriya $u$ zhenshchin s narusheniyami $v$ reproduktivnoy sisteme [Endometrial receptivity in women with impaired reproductive system] Zhurnal akusherstva i zhenskikh bolezney - Journal of Obstetrics and Female Diseases, 66, 4, 90-97 [in Russian].

8. Lukach, A.A. (2010). Giperplasticheskiye protsessy genitaliy, assotsiirovannyye $s$ infektsionnymi patogenam (patogenez, klinika, diagnostika) [Hyperplastic processes of the genitalia associated with infectious pathogens (pathogenesis, clinical presentation, diagnosis)]. Extended abstract of Doctor's thesis. Moscow [in Russian].

9. Vovk, I.B., Kornatska, A.H., Lysiana, T.O., Horban, N.Ye., \& Ponomarov, I.H. (2016). Osoblyvosti aerobnoi ta anaerobno mikroflory u zhinok z hiperproliferatyvnymy zakhvoriuvanniamy matky i endometriia [Peculiarities of aerobic and anaerobic microflora in women with hyperproliferative uterine diseases and endometrium]. Zdorovye zhenshchiny - Health of a Woman, 2, 102-106 [in Ukrainian].

10. Danshina, A.V. (2012). Mikroekologicheskiye osobennosti komponentov bioplenki reproduktivnogo trakta zhenshchin [Microecological features of the components of the biofilm of the reproductive tract of women]. Extended abstract of Doctor's thesis. Ulyanovsk [in Russian].

11. Franasiak, J.M., \& Scott, R.T.Jr. (2015). Reproductive tract microbiome in assisted reproductive technologies. Fertil. Steril. Dec., 104 (6), 1364-1371.

12. Dobrokhotova, Yu.E., \& Yakubova, K.K. (2018). Mikrobiota reproduktivnogo trakta i giperplasticheskiye protsessy endometriya (obzor literatury) [Reproductive tract microbiota and endometrial hyperplastic processes (literature review)]. RMZh. Meditsinskoye obozreniye - Russian Medical Journal. Medical Review, 10, 14-16 [in Russian].

13. Kurman, R.J., Kaminski, P.F., \& Norris, H.J. (1985). The behavior of endometrial hyperplasia. A long-term study of "untreated" hyperplasia in 170 patients. Cancer, 56, 403-412.

14. Reed, S.D., Newton, K.M., Clinton, W.L., Epplein, M., Garcia, R., \& Allison, K. (2009). Incidence of endometrial hyperplasia. Am. J. Obstet. Gynecol., 200, 678, e1-6.

15. Lax, S.F. (2016). Endometritis: Rare disease with clinical importance? Der Pathologe, (6), 521-525. doi: 10.1007/ s00292-016-0237-x.

16. Radzinskiy, V.E., Petrov, Yu.A., \& Kalinina, E.A. (2017). Patogeneticheskie osobennosti makrotipov khronicheskogo endometrita [Pathogenetic features of macrotypes of chronic endometritis]. Kazanskiy meditsinskiy zhurnal - Kazan Medical Journal, 1 (98), 27-34 [in Russian].

17. Ashkhab, M.Kh., Vladimirtseva, A.L., Shelyastina, N.N., \& Babichenko, I.I. (2002). Immunogistokhimicheskiye issledovaniya ekspressii retseptorov steroidnykh gormonov v endometrii zhenshchin v khode normalnogo menstrualnogo tsikla [Immunohistochemical studies of the expression of steroid hormone receptors in the endometrium of women during the normal menstrual cycle]. Vestnik RUDN, ser. Meditsina. Akusherstvo i ginekologiya - Bulletin of PFU, series Medicine. Obstetrics and Gynecology, 1 [in Russian].

18. Tabakman, Yu.Yu. (2009). Rak endometriya: rukovodstvo dlya vrachey [Endometrial cancer: a guide for physicians]. Moscow: Prakticheskaya meditsina [in Russian].

19. ACOG Committee Opinion No. 631. "Endometrial intraepithelial neoplasia." Obstet. Gynecol., 125 (2015), 12721278.

20. Kurman, R.J., Carcangiu, M.L., Herrington, C.S., \& Young, R.H. (Eds.). (2014). WHO Classification of tumours of female reproductive organs. 4 th ed. Lyon: IARC.

21. Kerivnytstvo po klinichnomu vedenniu hiperplazii endometriia Honkonhskoho koledzhu akusheriv i hinekolohiv (HKCOG) № 16 vid veresnia 2015 roku [Guidelines for the clinical management of endometrial hyperplasia at the Hong Kong College of Obstetricians and Gynecologists (HKCOG) No. 16 of September 2015].

22. Kerivnytstvo Korolivskoho koledzhu akusheriv i hinekolohiv (RCOG) ta Brytanskoho tovarystva z hinekolohichnoi endoskopii (BSGE) № 67 vid liutoho 2016 roku [The Royal College of Obstetricians and Gynecologists (RCOG) and the British Society for Gynecological Endoscopy (BSGE) No. 67 of February 2016]. [in Ukrainian].

23. Sergeyev, P.V., Shimanovich, N.L., \& Petrov, V.I. (1999). Retseptory fiziologicheski aktivnykh veshchestv [Receptors of physiologically active substances]. Volgograd: Sem vetrov [in Russian]. 